\title{
Health Care and Medical Education to Promote Women's Health in Iran; Four Decades Efforts, Challenges and Recommendations
}

\author{
Shima Tabatabai, $\mathrm{PhD}^{1 *}$; Nasser Simforoosh, $\mathrm{MD}^{2}$ \\ ${ }^{1}$ Medical Ethics and Law Research Center, Shahid Beheshti University of Medical Sciences, Tehran, Iran \\ ${ }^{2}$ Urology and Nephrology Research Center, Department of Urology, Shahid Labbafinejad Medical Center, Shahid Beheshti University of \\ Medical Sciences, Tehran, Iran
}

\begin{abstract}
Background: The aim of this paper is to present a synthesis of solutions for post-graduate medical education (PGME) and the health-care system in addressing challenges in relation to women's health.

Methods: A critical review was conducted within three themes: women's health status, women's preferences for female physicians, and women in surgery. The study was conducted in two phases that consisted of an analysis of the trends of Iranian women's health and women's participation in PGME since 1979 followed by a thematic analysis to assess the current challenges and their implications on medical education.

Results: Our analysis revealed important trends and challenges. Since 1979, life expectancy has increased by $29 \%$ in Iranian women, while female adult mortality rate has decreased by $78 \%$, and maternal mortality rate has decreased by $80 \%$. The number of female medical specialists has increased by $933 \%$, while the number of female subspecialists has increased by $1700 \%$. According to our review, ten major challenges regarding women's health were identified: 1) Increase in chronic disease; 2) Increase in cancer cases; 3) Preference for same-gender physicians in sensitive procedures; 4) Delayed care-seeking due to lack of female surgeons; 5) Lack of gender-concordance in clinical settings; 6) Underestimating female surgeons' capabilities; 7) Female physicians' work-family conflicts; 8) Male-dominancy in surgical departments; 9) Women's under-representation in higher rank positions; and 10) Lack of women in academic leadership.

Conclusion: We identified different solutions to bridge these gaps. Community-based education, Gender-concordant considerations, and empowering women in surgical departments could help medical education policy makers to address the challenges.

Keywords: Iran, Medical education, Trends, Women doctors, Women's health

Cite this article as: Tabatabai S, Simforoosh N. Health care and medical education to promote women's health in Iran; Four decades efforts, challenges and recommendations. Arch Iran Med. 2020;23(7):469-479. doi: 10.34172/aim.2020.44.
\end{abstract}

Received: July 26, 2019, Accepted: January 1, 2020, ePublished: July 1, 2020

\section{Introduction}

Women constitute nearly half the population of the world, but their role in strengthening social structure is way beyond this figure. Women's health has an essential role in family health and social development. ${ }^{1,2}$ Based on the religious doctrine, apart from their family roles, women in Iran enjoy commendable respect in their social roles. So health authorities need to devote considerable attention to women's health and wellbeing. ${ }^{3}$ Following the revolution of 1979, promoting mother and child health was determined as one of the most important priorities of Iran's ministry of health and medical education (MOHME). ${ }^{3}$ Over the last decades, Iran has witnessed remarkable achievements in the health and medical education systems, resulting in the increased efficiency of mother and child healthcare. ${ }^{4}$

Gender is a social determinant of health, and women's health issues differ from that of men in many unique ways. ${ }^{5}$ Meanwhile, it cannot be ignored that the World Health Organization (WHO) has categorized women as vulnerable, due to physiological changes women go through in their lives including menstruation, pregnancy, and menopause and their important role as mothers in the family. ${ }^{1}$ Women's health is influenced not just by their biology but also by economic conditions as well as social and family responsibilities. Further, discrimination against women in many countries restricts their access to the necessities of life, including health care. ${ }^{6}$ Women's health and well-being are monitored by multiple indicators. ${ }^{1}$ These determinants of health give rise to health needs and inequalities across regions and populations. ${ }^{7}$

The factors affecting women's health are complex. In this regard, our study focuses on three broad themes applicable in all contexts including 'women's health indicators and aspects', 'women's preferences for same-gender physicians', and 'women's participation in PGME and Academic leadership'. The achievements of the Iranian MOHME and current worldwide challenges are presented in detail in the results.

Although there is a growing body of literature explaining women's health needs and challenges, ${ }^{1-10}$ it is 
not clear how the medical education system can play an effective role to bridge the gaps. In this study, we aimed at answering this question in order to improve post-graduate medical education (PGME) and the health-care system to incorporate national priorities in addressing women's health challenges.

\section{Materials and Methods}

This study systematically identified, critically appraised, thematically analyzed and synthesized studies related to women's health challenges and facilitators for strengthening health and medical education system to promote women's health in Iran. To begin organizing the structure of the literature review, one reviewer performed a preliminary review and analysis. Since women's health priorities and related challenges vary globally, we needed to identify relationships between the sources we reviewed. Based on our readings and notes, we looked for the themes which were the recurring concepts across the literature. This preliminary analysis was discussed with the other author and some academic experts from women's health department. This thematic review provides an in-depth examination of principles through evaluation of relevant objectives. It focuses on a central element which is taken into consideration from different point of views. Finally, three broad themes were selected to conduct the critical review and thematic analysis in two phases. The first phase was conducted to analyze the existing evidence on trends and the achievements of different aspects related to women's health. The second phase was conducted to categorize the health and medical educations system challenges related to women's health promotion. The existing empirical and theoretical studies were summarized to provide more comprehensive recommendations.

\section{Data Collection}

The keywords and various combinations of the key terms included 'Iranian women', 'women health', ' health indicators', 'epidemiological transition', 'challenge', 'woman health promotion', 'medical education', 'gender gap', 'women physicians', 'female specialists', 'surgeon', 'obstacle', 'barrier', 'gender-based discrimination', 'masculine culture', 'glass ceiling', 'work-life balance', 'parttime', 'family', 'career', 'academic leadership', 'satisfaction', 'surgical specialty', 'surgical departments' and Boolean operators 'AND, OR' were used to increase the sensitivity of our search. To be more precise, we excluded the studies that focused on psychological aspects of women's health, and disciplines other than medicine. Also, the reference lists in the literature were searched manually. Initially, the electronic databases including MEDLINE, PubMed, Science Direct, Scopus, and Google Scholar were searched in March 2019 which was limited to the studies published after January 1999. To find any possible new publication, the search was updated in June 2019. The best existing evidence and data on women's health in Iran were retrieved from MOHME national reports, national cancer registry report, and scientific electronic databases and our previous national research supported by the academy of medical sciences on growth of women in PGME.

\section{Inclusion and Exclusion Criteria}

Papers published in English were included in the review. Articles including editorials, commentary, and studies irrelevant to the research question were excluded. The duplicate references were removed both automatically and manually (Figure 1).

\section{Data Analysis}

Thematic analysis was used to identify key challenges from the reviewed articles. With repeated reading of data extracted from the articles, the text segments that were related to the study objective were identified. Finally, the data were coded into a total of ten challenging themes. Completing the open coding, themes and subthemes were assigned to them. Then, the literature was qualitatively synthesized followed by matching of the identified challenges with their solutions to meet the women's health priority.

Both authors participated in critical review and synthesis of evidence. Through these discussions, more themes for challenges began to emerge. Any discrepancies were resolved by consensus, thereby validating the final results. The percentage change that represents the degree of change over time and was calculated using the following formula:

$$
\begin{aligned}
& \text { Percentage Change (where } v 1 \text { is } 1 \text { st value \& } v 2 \text { is } 2 \text { nd value) } \\
& =\left(\frac{v 2-v 1}{v 1}\right) * 100
\end{aligned}
$$

\section{Results}

Our analysis revealed important current growth trends and ten challenges. The results are presented in three selected themes. The sub-sections of each theme begin with a descriptive summary of the current trends and achievements and then continue with identified challenges.

\section{Women's Health Indicators and Different Aspects}

Table 1 summarizes the status of selected indicators related to women's health and the significant changes in women's health over the last decades in IR Iran.

According to the 2016 census results released by the Statistical Center of Iran, women comprise $49.3 \%$ of the population. ${ }^{9}$ The Iranian population profile showed increasing aging and urbanization rate. ${ }^{10,11}$ Life expectancy (LE) is known as a distinct index of development. Iranian women's LE is on the rise, ${ }^{11,12}$ while general fertility, mother/ infant mortality rate, female mortality rate, diseases related to pregnancy/childbirth, and communicable disease mortality rate are declining (Table 1 ). ${ }^{13-16}$ 


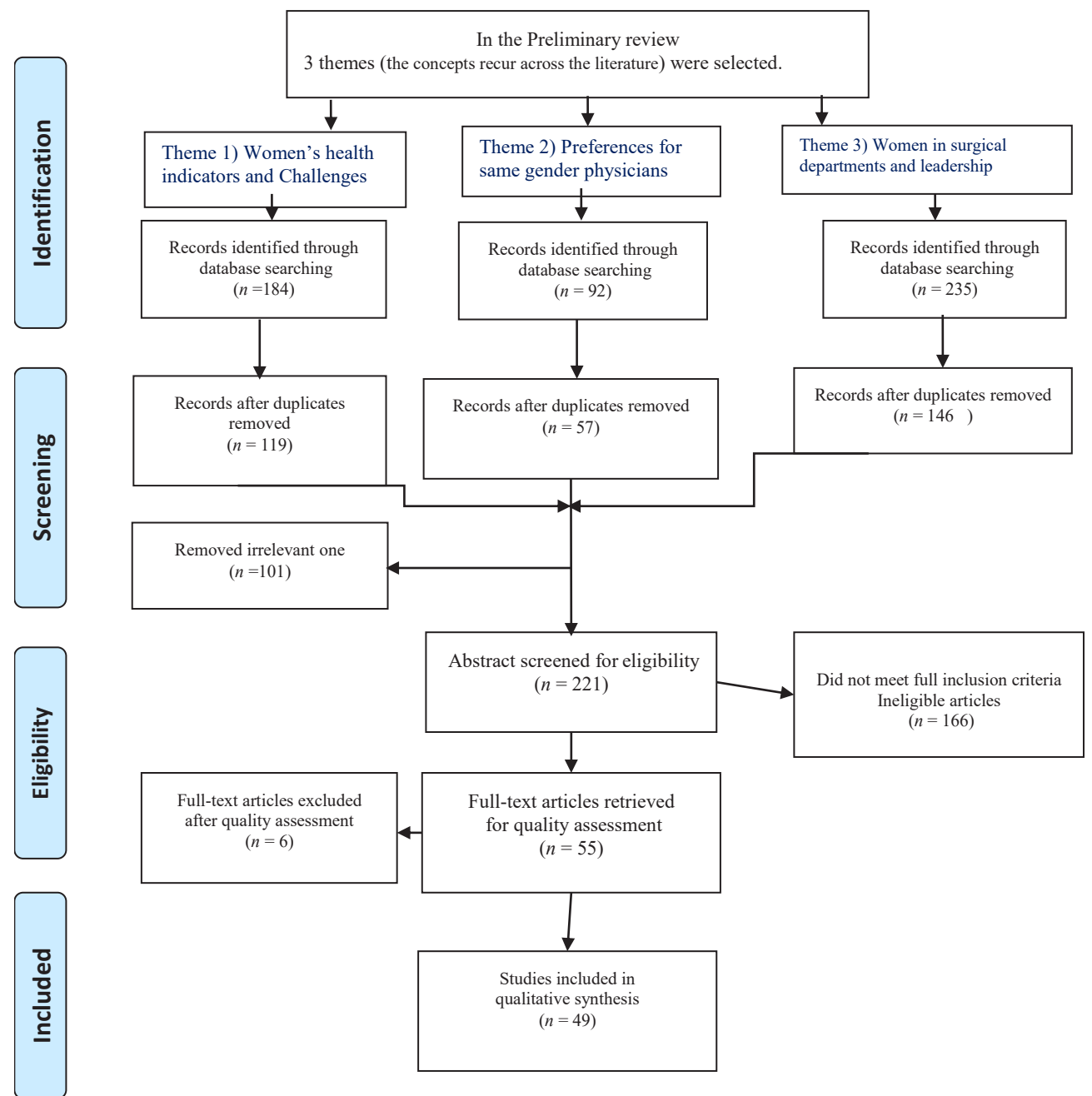

Figure 1. Flow of Information through the Different Phases of the Review.

\section{Challenge 1. Increase in Chronic Diseases}

The health profile is influenced by the demographic and epidemiological transition. The prevalence of chronic noncommunicable diseases is increasing globally. The issue of aging, paired with increasing life expectancy, will bring about long years of living with co-existing conditions such as heart disease and hypertension among the elderly. ${ }^{8,17}$ The urbanization index has increased by 60\% since 1976 (Table 1). Urban life has brought about numerous health problems, especially for women.

\section{Challenge 2. Increase in Cancers}

According to the WHO report in 2010, 72\% of deaths in Iran are due to non-communicable disease, and $12 \%$ were caused by cancers. ${ }^{18}$ Cancer is growing at an alarming rate and is a major threat to the health system. As reported by the WHO, the percentage of cancer patients is on the rise. Cancer is a major problem in Europe and generally causes more than $20 \%$ of deaths in women. ${ }^{19}$ As stated in recent studies, cancer is the third cause of death in Iran, after cardiovascular diseases and road accidents. As the country's elderly population increases, cancer will become epidemic. ${ }^{20}$ This is also the case around the globe, as the number of cancer patients has almost doubled annually by $2020 .{ }^{18}$ The national cancer registry reported breast cancer as the most prevalent cancer in Iranian women. Ovary cancer was the most prevalent, and cervical cancer was the least prevalent one in the reproductive system. ${ }^{21}$

Women's Preferences for Female Specialists and Surgeons In our literature review, a considerable number of studies investigated the patients' preferences for their physicians' gender. ${ }^{23-27}$ We identified that most of women prefer female surgeons for sensitive procedures. ${ }^{25-36}$ Women's preferences for same-gender specialists are highly sensitive and have numerous foundations such as culture, religion, past experiences, and physicians' practice style that can affect a person's comfort level. ${ }^{22,24-27}$

In 1985, the Iranian MOHME decided that only female physicians were admitted to the Ob-Gyn specialty education due to female patients' demand and right for same-gender Ob-Gyns.,23 Over the last decades, the number of female residents entering all specialist fields and therefore, the number of female specialists have increased 
Table 1. Status of Selected Indicators Related to Women's Health in Iran

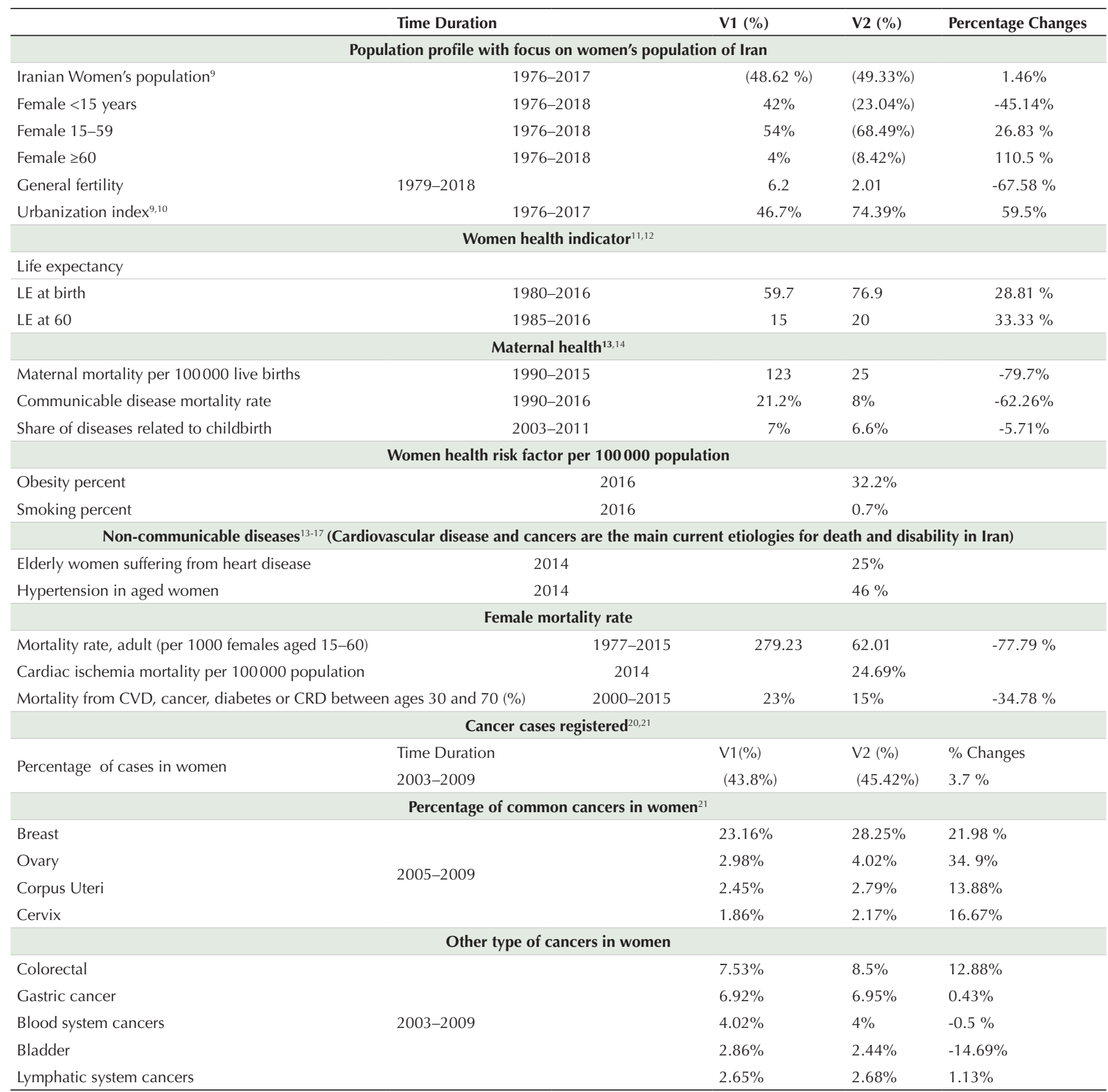

V1, 1st Value; V2, 2nd Value; LE, Life Expectancy; CVD, Cardio-Vascular Disease; CRD, chronic respiratory disease.

in Iran. Figure 2 shows that the women's numbers in Ob-Gyn specialty have increased much more than other specialties.

Challenge 3. Increasing Demand for Female Physicians and Surgeons in 'Sensitive' Medical Visits and the Supply There is an increasing preference for female physicians concerning their practice style. Female surgeons respond to the socialization demand of their female patients with their care, warmth, patience, and empathy. ${ }^{24}$ Increasingly, male medical students report being refused by female patients, particularly in obstetrics and gynecology, which impacts recruitment into the discipline. ${ }^{26}$ A study to assess the gender preferences of women regarding their choice of a breast surgeon showed that about a third of women prefer a female breast surgeon for their breast examination. ${ }^{25}$ Embarrassment during the examination was the major reason for same-gender preference. ${ }^{26}$ Urologic problems are among other highly sensitive issues for women regarding the physician's gender. ${ }^{27,28} \mathrm{~A}$ study in 2017 showed that more than half the female participants had a preference for same-gender urologists. ${ }^{29}$ Pregnant Muslim women usually seek female obstetricians for prenatal care and prefer to have a female doctor present at delivery. ${ }^{30}$ Another study showed that $90.6 \%$ of women do not select male Ob-Gyns. ${ }^{31}$ Studies which investigated patients' physician gender preference in the emergency department (ED) settings have shown that in the 'routine' 


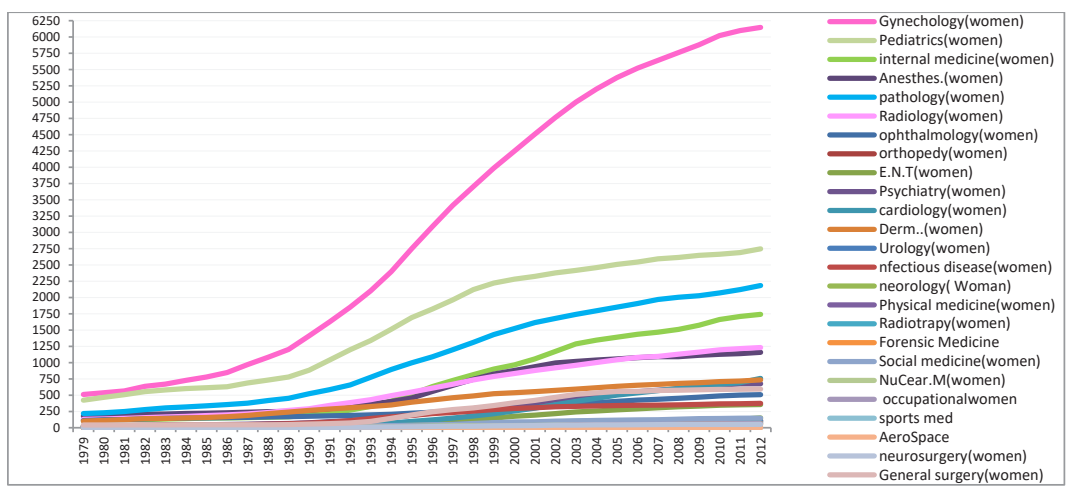

Figure 2. Growth Trends of Female Specialists in All Specialty Fields in Iran Since 1979.

visits and 'sensitive' medical visits, there is a propensity for same-sex physician preference. There is a considerable preference for the presence of a female physician in the ED to handle gastrointestinal diseases, clinical assessment, non-life-threatening cases, and physical examination for female patients. ${ }^{32}$

Challenge 4. Delays in Care Seeking Due to a Perceived Lack of Female Clinicians

We identified that many Asian women and many devout Muslim women delayed care seeking due to a perceived lack of female clinicians and may have very advanced disease by the time they seek medical help. Delayed care seeking is associated with adverse health outcomes. ${ }^{25,33,34}$

Challenge 5. Lack of a Comprehensive Approach to Fulfill the Need for Gender-concordant Health Care Provider Model Based on Islamic Principles in Health and Medical Education System

Lack of gender-concordant providers can be a barrier to timely care. Studies show that American Muslims not only request for the physician but also care providers of the same gender because of their Islamic values and concerns about preserving modesty. ${ }^{35,36}$ Some women refused male providers even in emergencies and refused male anesthesiologists when female physicians were not available. ${ }^{33-35}$

Women's Participation in Postgraduate Medical Education and Higher Rank Academic Positions

There has been a remarkable increase in female specialists and subspecialists since 1979 (Table 2). Women doctors now account for over $50 \%$ of total residents. Most women entered non-surgical subspecialty fields (Table 3). Our results showed that ob-gyn, geriatrics, pediatrics, and dermatology are the specialties with the highest percentage of Iranian female physicians (Table 3).

Between 1979 to 2015, the total number of Iranian medical specialists increased by $332 \%$, while the greatest increase pertained to women with $933 \%$ (Table 2). The total number of active specialists increased by $332 \%$, while the number of active women specialists increased by more than $1000 \%$ (Table 2). The number of women subspecialists increased from 57 in 1979 to 1025 in 2015, showing a $1700 \%$ increase (compared with $528 \%$ increase for both women and men). Our results revealed that although the men's numbers have increased during these years, the women's increase has been greater (Table 2). The majority of women doctors are attracted to general care fields, while a smaller proportion of women enter surgical specialties and subspecialties. Also, the percentage of women interested in pediatric subspecialties continues to grow (Table 3). Today, one of the 65 medical science universities in Iran (1.5\%) is managed by a woman chancellor and about $35 \%$ of recruited faculties were women in $2017 .{ }^{37}$

Challenge 6. Underestimating Female Surgeons' Capabilities due to their Physiology

Historically, a 'masculine' or patriarchal culture was formed in medicine formed as a result of the dominance of biologically male doctors. Now, the term "masculine' is not restricted to the literal description of biological sex -essentialism- but is cultural. ${ }^{38}$ An argument was that surgeons must protect themselves by distancing themselves from carrying their patients' suffering and they must have stronger emotional repression mechanism, while the female physician cannot handle so much suffering. Studies emphasized that female doctors perceived continuous discrimination based on the patriarchal culture persisting with the male dominancy in medicine and experienced negative comments about their gender. ${ }^{24-38}$

Challenge 7. Obstacles (Work-family Conflict) Which Affect Female Doctors' Preference in Choosing Surgical Fields

Worldwide, female physicians have different preferences for specialty selection and working patterns compared to men. These differences will affect how the physician workforce evolves in the next ten to twenty years. ${ }^{39}$ Women perceived obstacles to career success in surgery such as difficulties in balancing family and professional life. ${ }^{40,41}$ 
Table 2. Iranian Women's Percentage Increase in Postgraduate Medical Education (Compared with Percentage Increase for Both Women and Men)

\begin{tabular}{|c|c|c|c|c|c|}
\hline & Gender & $\begin{array}{c}1979-1980 \\
\text { No. }(\%)\end{array}$ & $\begin{array}{l}2014-2015 \\
\text { No. }(\%)\end{array}$ & Percentage Changes & $\begin{array}{c}\text { Increase } \\
\text { (For the Numbers) }\end{array}$ \\
\hline \multirow{2}{*}{$\begin{array}{l}\text { Admitted in specialty } \\
\text { residency }\end{array}$} & Women admitted & $61(20 \%)$ & $1721(59 \%)$ & \multirow{2}{*}{$+195 \%$} & $2721.31 \%$ \\
\hline & Total (women and men) & $304(100 \%)$ & $2916(100 \%)$ & & $859.21 \%$ \\
\hline \multirow{2}{*}{ Reregistered specialists } & Women specialists & $1988(13 \%)$ & $20550(31 \%)$ & \multirow{2}{*}{$+146 \%$} & $933.7 \%$ \\
\hline & Total & $15410(100 \%)$ & $66590(100 \%)$ & & $332.1 \%$ \\
\hline \multirow{3}{*}{$\begin{array}{l}\text { Active specialists+ } \\
\text { residents }\end{array}$} & Women & $1550(12 \%)$ & $17950(38 \%)$ & & $1058.06 \%$ \\
\hline & Total & $12410(100 \%)$ & $46650(100 \%)$ & & $276 \%$ \\
\hline & & 1985 & 2015 & & \\
\hline \multirow{2}{*}{$\begin{array}{l}\text { Admitted in } \\
\text { subspecialty programs }\end{array}$} & Women admitted in subspecialty & $2(8 \%)$ & $94(35 \%)$ & \multirow{2}{*}{$+337.5 \%$} & $6400 \%$ \\
\hline & Total & $25(100 \%)$ & $330(100 \%)$ & & $1220 \%$ \\
\hline \multirow{2}{*}{ Subspecialists supply } & Women subspecialists & $57(8 \%)$ & $1025(22 \%)$ & \multirow{2}{*}{$+175 \%$} & $1698 \%$ \\
\hline & Total & $748(100 \%)$ & $4700(100 \%)$ & & $528.34 \%$ \\
\hline
\end{tabular}

Table 3. Specialties with Highest and Lowest Percentage of Women Doctors in 2014-2015

\begin{tabular}{|c|c|c|c|}
\hline \multicolumn{2}{|l|}{ Highest Percentage of Women } & \multicolumn{2}{|c|}{ Lowest Percentage of Women } \\
\hline Obstetrician-Gynecologist & $80 \%$ & General surgeon & $10 \%$ \\
\hline Geriatric medicine specialist & $50 \%$ & Emergency medicine Sp. & $10 \%$ \\
\hline Community medicine Sp. & $47 \%$ & Sports medicine Sp. & $10 \%$ \\
\hline Dermatologist & $40 \%$ & Urologist & $7 \%$ \\
\hline Pathologist & $40 \%$ & Neurosurgeon & $5 \%$ \\
\hline Pediatrics & $36 \%$ & Orthopedic surgeon & $4 \%$ \\
\hline Infectious disease specialist & $31 \%$ & Aerospace medicine & $0 \%$ \\
\hline Radiologist & $31 \%$ & & \\
\hline Occupational medicine Sp. & $30 \%$ & & \\
\hline \multicolumn{4}{|c|}{ Subspecialties with highest and lowest percentage of women doctors } \\
\hline Highest percentage of women & & Lowest percentage of wor & \\
\hline Child psychiatrist & $65 \%$ & Vascular surgeon & $0 \%$ \\
\hline Pediatric gastroenterologist & $51 \%$ & Thoracic surgeon & $2 \%$ \\
\hline Pediatric endocrinologist & $50 \%$ & Plastic surgeon & $2 \%$ \\
\hline Pediatric pulmonologist & $50 \%$ & Pediatric surgeon & $2 \%$ \\
\hline Neonatal-prenatal medicine & $44 \%$ & Cardiovascular surgeon & $2 \%$ \\
\hline Pediatric nephrologists & $40 \%$ & & \\
\hline
\end{tabular}

Female surgeons reported difficulties in balancing between family responsibilities (childcare duties, homecare duties), and excessive workload and on-call commitment. ${ }^{41}$ Studies revealed that female surgeons were satisfied with their choice of profession, but they were less satisfied with their work-life. Other studies described that excessive workload, the on-call duties, full-time commitments, work-related stress, frustration, and worry were often cited as the negative aspects of surgery and the reasons why female surgeons rated their level of job satisfaction to be moderate or dissatisfied. ${ }^{40-42}$

Challenge 8. Obstacles (Health and Medical Education System Barriers) Contributing to Male Dominancy in Surgical Departments

Studies showed that female academic surgeons experience challenges that are perceived to differ from their male colleagues. Historically specialties like urologic, orthopedic and plastic surgery have been male-dominated fields and lack of female colleagues and bias against women pursuing career in some surgical fields are other obstacles. ${ }^{38,42}$ Female surgeons perceived discrimination by the male power structure in surgery and felt excluded from the male dominant culture. Most of them are unsatisfied with their career advancement, unequal promotion, unequal pay and income, as well as lack of female mentors and research funding. ${ }^{43}$

Challenge 9. Mismatch between the Brilliant Women's Achievements in Postgraduate Medical Education and their Future Career

We identified a mismatch between the current achievements of women in medical specialty/subspecialty training and their future participation in top-level decision-making positions. International evidence indicates persistent under-utilization of women's expertise in leadership 
and higher rank positions in medical academia. Women reported feeling career advancement opportunities were not equally available to them as to their male peers. ${ }^{44,45}$

Challenge 10. Lack of a Comprehensive Approach in Preparing Female Medical Students and Residents for their Future Leadership Role in Health and Medical Education Systems

Women under-representation in academic leadership and top-level positions is a challenge worldwide. ${ }^{45}$ This phenomenon is called the 'glass ceiling', restricting female specialists and surgeons from promotion beyond a certain level. ${ }^{46}$ Women reported insufficient mentoring for their future leadership roles and insufficient access to professional networks as the constraints against reaching top-level positions. ${ }^{46-48}$

\section{Discussion}

To the best of our knowledge, this is the first comprehensive study to review the Iranian Health system achievements and current challenges in order to provide an integrative description of how we can promote health care and medical educations in meeting women's health priorities.

We selected three major themes contributing to women's health priorities in the health care and medical education system. Then, we analyzed four decades of achievements in the postgraduate medical education system in Iran for each of the three themes. The results are summarized in Tables 1-3 and Figure 2. Our analysis revealed that women's health indicators and women's participation in PGME have improved remarkably over the last 40 years. We identified ten major challenges for the selected themes regarding women's health needs (Table 4).

Strengthening the Health-care and Medical Education Systems to Promote Women's Health

Women empowerment in medical education, especially in specialty/subspecialty training, has a direct impact on women's health and community wellness. The health and medical education system authorities have to execute several interventions for current challenges. We propose ten recommendations and related implications for the health and medical education system to incorporate women's health priorities in Iran (Table 5).

In our first theme, we found many evidences and studies which had gathered data on women's health indicators in Iran. ${ }^{3,7-13}$ While analyzing these features, we found that other reviews consistently stated that women's health profile is influenced by the demographic and epidemiological transition, lifestyle changes, urban life, unhealthy food, stress, work pressure and lack of physical activity, use of alcohol and smoking, air pollution, and carcinogenic particles. ${ }^{14-21}$

The study of emerging trends and community needs (aging population health needs, preventive medicine, chronic disease, and need for disability management) allows health and medical education policymakers to make better decisions concerning future health issues of the country and reforming medical education and specialty/subspecialty training curriculum. Concerning the determinant of women's health, the most relevant interventions in the medical education system to meet women's health priorities were found to be communitybased medical education and alignment of medical curriculum with national health needs. ${ }^{49}$ Communitybased medical education is where national health priorities are addressed. Furthermore, inclusion of gender issues in medical curricula ${ }^{50}$ would prepare female specialists to work in partnership with female patients in self-care, providing sensitive cares, managing chronic diseases, and controlling the cause and consequences of prevalent cancers among Iranian women.

In our second theme, we found many articles which had gathered data from the perspective of patients or specialists, and used qualitative or quantitative methods to present detailed information about the patients' preference for

Table 4. Qualitative Synthesis for the Challenges in Health and Medical Education System, to Incorporate Women's Health Needs and Demands

\begin{tabular}{|c|c|c|c|}
\hline Theme & Trends & Challenges & \\
\hline $\begin{array}{l}\text { Women's health } \\
\text { indicators }\end{array}$ & $\begin{array}{l}\text { Demographic and epidemiological } \\
\text { transition }\end{array}$ & $\begin{array}{ll}1 . \\
2 .\end{array}$ & $\begin{array}{l}\text { Increase in chronic diseases among Iranian women population. } \\
\text { Increase in cancer cases among Iranian women. }\end{array}$ \\
\hline $\begin{array}{l}\text { Women preferences for } \\
\text { female physicians \& } \\
\text { care providers }\end{array}$ & $\begin{array}{l}\text { Increasing demand for female } \\
\text { physicians and care providers } \\
\text { based on } \\
\text { - } \quad \text { Religious and culture } \\
\text { - Past experiences and practice } \\
\text { patterns }\end{array}$ & $\begin{array}{l}3 . \\
4 . \\
5 .\end{array}$ & $\begin{array}{l}\text { Increasing demand of female patients for female physicians in 'sensitive' } \\
\text { medical visits. } \\
\text { Delays in care seeking due to a perceived lack of female clinicians. } \\
\text { Lack of comprehensive approach to fulfill the need for gender-concordant } \\
\text { health care provider model based on Islamic principles in health and medical } \\
\text { education system. }\end{array}$ \\
\hline $\begin{array}{l}\text { Women's physician } \\
\text { participation in PGME } \\
\& \text { academic leadership }\end{array}$ & $\begin{array}{l}\text {-Masculine" culture of } \\
\text { medical surgery } \\
\text { Patriarchal culture of } \\
\text { leadership } \\
\text { Glass ceiling at top-level } \\
\text { academic positions }\end{array}$ & $\begin{array}{l}6 . \\
7 . \\
8 . \\
9 . \\
10 .\end{array}$ & $\begin{array}{l}\text { Attitude of underestimating female surgeons' capabilities due to their } \\
\text { physiology. } \\
\text { Work-family conflict which affect choosing specialty and subspecialty fields. } \\
\text { Male dominancy in surgical departments. } \\
\text { Mismatch between the brilliant women's achievements in postgraduate } \\
\text { medical education and their future career. } \\
\text { Lack of a comprehensive approach in preparing women for their future } \\
\text { academic leadership roles in medical sciences universities. }\end{array}$ \\
\hline
\end{tabular}


Table 5. Recommendations Proposed to Promote Iranian Women's Health and to Meet Women's Challenges as Patients and as Physicians

\begin{tabular}{|c|c|c|}
\hline Theme & & Recommendations \& Implications for PGMED \\
\hline $\begin{array}{l}\text { Women's health } \\
\text { aspects }\end{array}$ & 1. & $\begin{array}{l}\text { Community based medicine: Need for changing curriculum focused on community needs (chronic disease and disability } \\
\text { management, prevention and self-care to control health risk factors). } \\
\text { Flexible curriculum for training gender issues: Need for preparing female physicians specifically for women's community health } \\
\text { demands through flexible curriculum. }\end{array}$ \\
\hline $\begin{array}{l}\text { Female patients' } \\
\text { preferences for } \\
\text { female Physicians } \\
\& \text { care-provider }\end{array}$ & $\begin{array}{l}3 . \\
4 .\end{array}$ & $\begin{array}{l}\text { To train more female physicians who are prepared to go into surgical specialties and subspecialty career paths less attractive to } \\
\text { women. } \\
\text { Respectfully responding to a female patient's request for a female provider considering the patient's values, sensitivity, and } \\
\text { preferences. } \\
\text { Taking a comprehensive approach to fulfill the need for gender-concordant care provider model based on Islamic principles in } \\
\text { Iran's health and medical education system. } \\
\text { Need to be sensitive to religious and cultural issues and concerns about preserving modesty, particularly for personal } \\
\text { examinations. } \\
\text { Need for establishing women's general educational hospitals compatible with the requirements for integrated women health care } \\
\text { services and gender-concordant providers demand in Iran. }\end{array}$ \\
\hline $\begin{array}{l}\text { Women's } \\
\text { empowerment } \\
\text { in PGME and } \\
\text { Academic } \\
\text { leadership }\end{array}$ & $\begin{array}{l}7 . \\
8 . \\
9 . \\
10 .\end{array}$ & $\begin{array}{l}\text { Increasing flexibility in training and work pattern for female physicians and providing institutional support for creating family- } \\
\text { friendly working conditions. } \\
\text { Changing the male-dominated culture of surgical departments in medical education system. } \\
\text { Supporting career advancement of competent female specialists and subspecialists. } \\
\text { Preparing female medical students and residents for their future leadership roles in medical education systems by offering proper } \\
\text { training programs. }\end{array}$ \\
\hline
\end{tabular}

same-gender physicians. International studies confirmed increasing women's preferences for female physicians, surgeons and care providers in different countries. ${ }^{24-30}$ Because of the perceived lack of female physicians, many women decide to delay care. Also, lack of genderconcordant providers could be a barrier to timely care. ${ }^{35}$ A study reported delays in care-seeking among American Muslim women because of the preference for female care providers due to their religious belief. ${ }^{25,35}$ Considering the population diversity, the health system needs to be sensitive to cultural differences, values, religious, and also societal norms. ${ }^{32-34,36}$ Therefore, providing patient-centered care for female patients requires considering religious beliefs, cultural issues, individual preferences, and concerns about preserving modesty, particularly for sensitive examinations.

While identifying the main challenges, we found that other studies had consistently stated that respecting women's preference for same-gender specialists was critical for women's health outcome. ${ }^{3,5,29-38}$ A cancer registry report showed a slight increase among women, calling for more attention to women's health in the country. Early detection of cancer is the key to controlling the disease, reducing mortality rate and improving the quality of life for patients and their families. Unlike screening which is administered in a healthy society, early detection, under the supervision of medical specialists/subspecialist, is for those who are at risk or feel sick. ${ }^{51}$ Many women who delay care-seeking to a perceived lack of female clinicians are at risk. ${ }^{25,34}$ The best strategies are to establish infrastructures, train more female medical specialists, and employ qualified care providers from both genders to perform sensitive procedures for the same-gender patients. Hospitals are responsible for considering patients' religious and spiritual beliefs as part of their rights and should provide care by same-gender care providers, especially for Muslim female patients. ${ }^{33}$
Establishing women's general educational hospitals compatible with the requirements for integrated women's health care services across multiple medical disciplines is an important practical solution for gender-concordant providers in Iran.

Iran's MOHME has long been concerned with the women-specific health issues concerning the cultural and social role of women in families and society. Iranian women, like most Asian and Muslim women, prefer female physicians, especially in sensitive medical procedures. Since1985, only women have entered the ObGyn specialty training programs and women's numbers in Ob-Gyn specialty have increased much more than other specialties in Iran (Figure 1). Over the last 40 years, Iran has made remarkable progress in women's presence in postgraduate medical education. Our analysis revealed that although the men's numbers have increased during these years, the increase has been greater for women (Table 2). Worldwide, ob-gyn, dermatology, and pediatrics have become specialties with the highest percentage of women. ${ }^{3,42-44}$ According to our study, pediatric related subspecialties have become the most attractive to female specialists, while surgical fields are less attractive (Table 3).

In the Islamic Republic of Iran in 2009, the first woman assigned to a position of Ministry was a gynecologist professor who became the Minister of Health and Medical Education. Despite some exceptional examples of the presence of some competent women in top positions in Iran's MOHME, evidence indicates persisting gender inequality in management positions and gender imbalance in top academic hierarchies.

Many studies have argued that the reason is an attitude of underestimating women in an academic higher rank leadership position. However, other studies have emphasized the institutional obstacles such as 
gender inequality, the male-dominant culture in surgery departments, and the unfriendly work structure. ${ }^{52-54}$ Certain structural supports including flexibility in training and working shifts, female-friendly environment, lower oncall duties, and part-time working practice arrangements to fit family responsibilities, and providing adequate facilities for childcare are recommended to attract more female physicians to surgical fields and retain female surgeons. ${ }^{55-56}$ Studies confirm that providing flexible and supportive work conditions for female surgeons would enable a more satisfactory balance between work and family. ${ }^{54-56}$

Attitudes and traditions related to the masculine nature of surgery and the culture of male dominance in surgical departments are perceived obstacles to career success for women. ${ }^{57}$ Attempting deeper changes in this culture will allow progress, and attract and retain the best surgeons regardless of gender. The number of women in tenured faculty positions in surgery departments remains limited. ${ }^{58,59}$ The greater presence of female surgeons as faculty members and mentors in surgical departments would motivate the female physicians entering surgical specialties. ${ }^{60,61}$ Increasing female faculty members and role models in surgical departments, and developing rich networks among female surgeons would produce meaningful change in the currently male-dominated culture in which male surgeons feel superior to female surgeons.

Although some efforts have been made to increase the recruitment of women as faculty members in medical universities in the last decade, about $65 \%$ of recruited faculties were men in 2017. Women still have lower tenure and promotion rates in Iran. ${ }^{37}$ Ensuring equal recruitment opportunity based on merit and not open to bias, providing appropriate development opportunities for women to advance their careers, an equal promotion pathway, equal income, and equal research funding are the main solutions to address the obstacles faced by female physician and faculty members in recruitment and promotion. ${ }^{42,45}$ The health and medical education systems need to pay significant attention to facilitators for career advancement for female specialists and subspecialists. Provision of career advancement seminars for women to receive top ranks at all levels of hierarchy, gender-sensitive appointment and promotion criteria are recommended to support competent female specialists and subspecialists. Increasing the number of female mentors and role models will change the male-dominated attitudes in some surgical departments.

Establishing a comprehensive structure for preparing female medical students and residents for their future leadership roles would contribute to expanding the number of female leaders in surgical specialties in medical education systems. Female doctors are still not moving into leadership roles. ${ }^{61}$ To be selected as a senior manager, it is necessary to have related qualifications and experiences. Networking as a key to women's career success enables female medical students and residents in male-dominated specialties to share their knowledge and expertise. ${ }^{49}$ Female mentors motivate female residents and support them with appropriate information. The diverse experience of women across different managerial levels can prepare them for their future senior educational leadership roles. Legislations could be put in place to ensure the inclusion of women in senior academic roles. It is recommended that medical education institutes should offer proper training programs for gender-sensitive clinical and educational leadership such as mentoring programs, training workshops to prepare women for their future educational leadership roles. Universities should encourage female physicians to compete with their male colleagues to reach the top academic ranks and managerial levels. These changes could guarantee a cultural shift to empower women in top positions in the postgraduate medical education system.

Women's health needs vary globally, and it is beyond the scope of this paper to address the extent to which medical education has met all nationally defined needs. Considering the broad topic, we used a pragmatic approach for our literature review in three themes.

In conclusion, this article is solution-focused and allows health and medical education authorities to adopt policies to enhance women's health in the country. Over the last decades, great advancement has been made in the health and medical education system to improve health status for Iranian women. To continue this trend, the health care and medical education system will have to be aligned with women's aging population health needs, changing patterns of diseases, and increasing demand for same-gender physicians.

Our research highlights the need for gender-concordant physicians in sensitive cares for Iranian women. As Iran's health care and medical education systems continue to plan for providing effective health care for Iranian women, it is vital that authorities pay significant attention to their strong preferences for same-gender care providers and develop a policy on how to provide optimal care for women.

We recommend that MOHME develops cooperative health-care and educational strategies to effectively bridge the gaps between women's health priorities and PGME. Over the last four decades, Iran's medical education system has undergone major reforms, shifting from male-dominant medical universities to a system where all talented applications can enter undergraduate and PGME, without influence from gender bias. Continuing this trend and increasing the number of under-represented women in surgical departments will require attention to recruitment and mentorship. Furthermore, women empowerment in higher surgical academic ranks has a direct impact on women's health and community wellness. Medical sciences 
universities need to open doors to women to take top-level positions by improving gender-equity in the promotion process, especially in the appointment of professors.

Taking a comprehensive approach to fulfill women's health needs and develop a futuristic curriculum that will adequately prepare female physicians and surgeons to address women's health demands would be an important task of medical education policymakers in Iran.

\section{Authors' Contribution}

ST managed the overall design of the study, wrote the draft and analysed the data. ST and NS conceptualised this study, completed the manuscript and inspected the quality of data.

\section{Conflict of Interest Disclosures}

None declared.

\section{Ethical Statement}

All the ethical issues related to critical review and thematic synthesis of evidences were observed.

\section{Acknowledgements}

This article is extracted from a comprehensive national research supported by the Academy of Medical Sciences of Iran, and Dr. Shima Tabatabai's postdoctoral research in Medical Education supervised by Professor Dr. Nasser Simforoosh at Shahid Beheshti University of Medical Sciences.

\section{References}

1. WHO. Women and health: today's evidence tomorrow's agenda. 2009. Available from: https://www.who.int/genderequity-rights/knowledge/9789241563857/en/. Accessed May 2019.

2. Ahmadi B, Salavati S. National Women's Health Plan, Selected Countries Experiences and Necessity of Developing It in Iran. Iran J Public Health. 2019;48(1):32-42. doi: 10.18502/ijph. v48i1.780.

3. Simforoosh N, Ziaee SA, Tabatabai SH. Growth trends in medical specialists' education in Iran; 1979-2013. Arch Iran Med. 2014;17(11):771-5.

4. Khabiri R, Elahi E1, Khodayari E, Rashidian A. Maternal Health Care based on Iran'Multiple Indicator Demographic and Health Survey (IrMIDHS-2010). Hakim Res J. 2014;17(1):6777.

5. Vlassoff C, Garcia Moreno C. Placing gender at the centre of health programming: challenges and limitations. Soc Sci Med. 2002;54(11):1713-23. doi: 10.1016/s0277-9536(01)00339-2.

6. Mezey G, Bacchus L, Bewley S, White S. Domestic violence, lifetime trauma and psychological health of childbearing women. BJOG. 2005;112(2):197-204. doi: 10.1111/j.14710528.2004.00307.x.

7. Buck D, Maguire D. Inequalities in Life Expectancy: Changes Over Time and Implications for Policy. The King's Fund. 2015. Available from: https://www.kingsfund.org.uk/sites/ default/files/field/field_publication_file/inequalities-in-lifeexpectancy-kings-fund-aug15.pdf.

8. Frenk J, Chen L, Bhutta ZA, Cohen J, Crisp N, Evans T, et al. Health professionals for a new century: transforming education to strengthen health systems in an interdependent world. Lancet. 2010;376(9756):1923-58. doi: 10.1016/ S0140-6736(10)61854-5.

9. Statistical Center of Iran. Population and Housing Censuses. CENSUS 2016. Available from: https://www.amar.org.ir/ english/Population-and-Housing-Censuses/Census-2016.

10. Statista. Urbanization in Iran 2018. Jan 27, 2020. Available from: https://www.statista.com/statistics/455841/urbanization-in-iran/.

11. Fanni Z. Cities and urbanization in Iran after the Islamic revolution. Cities. 2006;23(6):407-11. doi: 10.1016/j. cities.2006.08.003

12. WORLD HEALTH RANKINGS. HEALTH PROFILE: IRAN. Accessed January 20, 2019. Available from: https://www. worldlifeexpectancy.com/country-health-profile/iran.

13. WHO, UNICEF, UNFPA, World Bank Group and the United Nations Population Division estimates. Trends in Maternal Mortality: 1990 to 2015. 2015. Available from: https:// apps.who.int/iris/bitstream/handle/10665/193994/WHO_ RHR_15.23_eng.pdf? sequence $=1$.

14. Malekzadeh R. Global Burden of Disease Study 2010: a real advance in global descriptive epidemiology: prospective for developing countries. Arch Iran Med. 2014;17(5):302-3.

15. IndexMundi. Iran - Mortality rate. Available from: http://www. indexmundi.com/facts/iran/mortality-rate.

16. Forouzanfar MH, Sepanlou SG, Shahraz S, Dicker D, Naghavi P, Pourmalek F, et al. Evaluating causes of death and morbidity in Iran, global burden ofdiseases, injuries, and risk factors study. Arch Iran Med. 2014;17(5):304-20.

17. Barnett K, Mercer SW, Norbury M, Watt G, Wyke S, Guthrie B. Epidemiology of multimorbidity and implications for health care, research, and medical education: a cross-sectional study. Lancet. 2012;380(9836):37-43. doi: 10.1016/S01406736(12)60240-2.

18. Jemal A, Bary F, Center MM, Ferlay J, Ward E. Global cancer statistics. CA Cancer J Clin. 2011;61(2):69-90. doi:10.3322/ caac. 20107.

19. Ferlay J, Forman D, Mather C, Bray F. Breast and cervical cancer in 187 coutries between 1980 and 2010. Lancet. 2012;379(9824):1390-1. doi: 10.1016/S01406736(12)60595-9.

20. World Life Expectancy. World Total Deaths. Available from: https://www.worldlifeexpectancy.com/world-rankings-totaldeaths.

21. Global Health Data Exchange. Iran National Cancer Registry 2009. Available from: http://ghdx.healthdata.org/record/irannational-cancer-registry-2009.

22. Moettus A, Sklar D, Tandberg D. The effect of physician gender on women's perceived pain and embarrassment during pelvic examination. Am J Emerg Med. 1999;17(7):635-7. doi:10.1016/s0735-6757(99)90148-1.

23. Tabatabai S, Simforoosh N, Ziaee SA. Iran's Postgraduate Medical Education Achievements over Last 35 Years. J Adv Med Med Res. 2015;10(1):1-6. doi: 10.9734/BJMMR/2015/19256.

24. Boulis AK, Long JA. Gender differences in the practice of adult primary care physicians. J Women's Health. 2004;13(6):70312. doi:10.1089/jwh.2004.13.703.

25. Hasnain M, Connell KJ, Menon U, Tranmer PA. Patientcentered care for Muslim women: Provider and patient perspectives. J Womens Health. 2011;20:73-83. doi:10.1089/ jwh.2010.2197.

26. McLean $\mathrm{M}, \mathrm{Al}$ Ahbabi $\mathrm{S}, \mathrm{Al}$ Ameri $\mathrm{M}, \mathrm{Al}$ Yahyaei $\mathrm{F}$, Bernsen R. Muslim women and medical students in the clinical encounter. Med Educ. 2010;44(3):306-15. doi:10.1111/ j.1365-2923.2009.03599.x.

27. Tabatabai S, Simforoosh N. Preference for patient -urologist gender similarity and its implications for urology departments: systematic narrative review and thematic analysis. Urol J. 2020. doi:10.22037/uj.v0i0.5779.

28. Simforoosh N, Tabatabai S, Ziaee SA. Achievements in postgraduate urologic education in Iran: a quantitative study. Urol J. 2014;10(4):1119-25.

29. Kim SO, Kang TW, Kwon D. Gender Preferences for urologists: women prefer female urologists. Urol J. 2017;14(2):30183022. 
30. Howell EA, Gardiner B, Concato J. Do women prefer female obstetricians? Obstet Gynecol. 2002;99(6):1031-5. doi: 10.1016/s0029-7844(02)01980-4.

31. Plunkett BA, Kohli P, Milad MP. The importance of physician gender in the selection of an obstetrician or a gynecologist. Am J Obstet Gynecol. 2002;186(5):926-8. doi: 10.1067/ mob.2002.123401.

32. Nolen HA., Moore JX, Rodgers JB., Wang HE, Walter LA. Patient Preference for Physician Gender in the Emergency Department. Yale J Biol Med. 2016;89(2):131-42.

33. Alqufly AE, Alharbi BM, Alhatlany KK, Alhajjaj FS. Muslim female gender preference in delaying the medical care at emergency department in Qassim Region, Saudi Arabia. J Family Med Prim Care. 2019;8(5):1658-63. doi: 10.4103/ jfmpc.jfmpc_141_19.

34. Vu M, Azmat A, Radejko T, Padela Al. Predictors of delayed healthcare seeking among American Muslim women. J Womens Health. 2016;25(6):586-93. doi: 10.1089/ jwh.2015.5517.

35. Ezenkwele UA, Roodsari GS. Cultural competencies in emergency medicine: caring for Muslim-American patients from the Middle East. J Emerg Med. 2013;45(2):168-74. doi: 10.1016/j.jemermed.2012.11.077.

36. Rajaram SS, Rashidi A. Asian-Islamic women and breast cancer screening: A socio-cultural analysis. Women Health. 1999;28(3):45-58. doi: 10.1300/J013v28n03_04.

37. Ministry of Health and Medical Education (MOHME). Reports. Accessed Feb 22, 2017.

38. Hamberg K. Gender perspective relevant in many medical school subjects. Essential to perceive men and women holistically. Lakartidningen. 2003;100:4078-83.

39. Tabatabai S, Javadi MA. Ophthalmic Education and Ophthalmologists Growth Trends in Iran (1979-2016). J Ophthalmic Vis Res. 2019;14(2):185-194. doi: 10.4103/jovr. jovr_24_18.

40. Streu R, McGrath MH, Gay A, Salem B, Abrahamse P, Alderman AK. Plastic surgeons' satisfaction with work-life balance: results from a national survey. Plast Reconstr Surg. 2011;127(4):1713-19. doi: 10.1097/PRS.0b013e318208d1b3.

41. Hebbard PC, Wirtzfeld DA. Practice patterns and career satisfaction of Canadian female general surgeons. Am J Surg. 2009;197(6):721-7. doi: 10.1016/j.amjsurg.2008.03.006.

42. Crompton R, Lyonette C. Women's career success and worklife adaptations in the accountancy and medical professions in Britain. Gender Work Org. 2011;18(2):231-54. doi: 10.1111/j.1468-0432.2009.00511.x.

43. Zutshi M, Hammel J, Hull T. Colorectal surgeons: gender differences in perceptions of a career. J Gastrointest Surg. 2010;14(5):830-43. doi:10.1007/s11605-010-1174-2 .

44. Schroen AT, Brownstein MR, Sheldon GF. Women in academic general surgery. Acad Med. 2004;79(4):310-18. doi:10.1097/00001888-200404000-00006.

45. Zhuge $\mathrm{Y}$, Kaufman J, Simeone DM, Chen $\mathrm{H}$, Velazquez OC. Is There Still a Glass Ceiling for Women in Academic Surgery? Ann Surg. 2011;253(4):637-43. doi: 10.1097/ SLA.0b013e3182111120.

46. Oakley J. Gender-based barriers to senior management positions: understanding the scarcity of female CEOs. J Bus
Ethics. 2000;27:321-34. doi: 10.1023/A:1006226129868. 47. Ahmadiyeh N, Cho NL, Kellogg KC, Lipsitz SR, Moore Jr FD, Ashley SW, et al. Career satisfaction of women in surgery: perceptions, factors, and strategies. J Am Coll Surg. 2010;210(1):23-8. doi: 10.1016/j.jamcollsurg.2009.08.011.

48. Davis EC, Risucci DA, Blair PG, Sachdeva AK. Women in surgery residency programs: evolving trends from a national perspective. J Am Coll Surg. 2011;212(3):320-6. doi: 10.1016/j.jamcollsurg.2010.11.008.

49. Worley P, Prideaux D, Strasser R, Magarey A, March R. Empirical evidence for symbiotic medical education: a comparative analysis of community and tertiarybased programmes. Med Educ. 2006;40(2):109-16. doi: 10.1111/j.1365-2929.2005.02366.x.

50. Ludwig S, Oertelt-Prigione S, Kurmeyer C, Gross M, GrütersKieslich A, Regitz-Zagrosek V, et al. A Successful Strategy to Integrate Sex and Gender Medicine into a Newly Developed Medical Curriculum. J Womens Health. 2015;24(12):9961005. doi: 10.1089/jwh.2015.5249.

51. Henderson JT, Weisman CS. Physician gender effects on preventive screening and counseling: an analysis of male and female patients' health care experiences. Med Care. 2001:39(12):1281-92. doi: 10.1097/00005650-20011200000004 .

52. Lautenberger DM, DandarVM, Raezer CL, Sloane RA. The state of women in academic medicine: the pipeline and pathways to leadership, 2013-2014. Available from: https://store.aamc. org/downloadable/download/sample/sample_id/228/.

53. Carnes M, Morrissey C, Geller SE. Women's health and women's leadership in academic medicine: hitting the same glass ceiling?. J Womens Health. 2008;17(9):1453-62. doi: 10.1089/jwh.2007.0688.

54. Angell M. Shattering the glass ceiling. JAMA Intern Med. 2014;174(4):6356. doi: 10.1001/jamainternmed.2013.13918.

55. Gjerberg E. Gender similarities in doctors' preferences and gender differences in final specialisation. Soc Sci Med. 2002;54(4):591-605. doi: 10.1016/s0277-9536(01)00054-5.

56. Dornhorst A, Cripps J, Goodyear H, Marshall J, Waters E, Boddy SA. Improving hospital doctors' working lives: online questionnaire survey of all grades. Postgrad Med J. 2005;81(951):49-54. doi: 10.1136/pgmj.2004.029512.

57. Park J, Minor S, Taylor RA, Vikis E, Poenaru D. Why are women deterred from general surgery training?. Am J Surg. 2005;190(1):141-6. doi: 10.1016/j.amjsurg.2005.04.008.

58. Mayer KL, Perez RV, Ho HS. Factors affecting choice of surgical residency training program. J Surg Res. 2001;98(2):71-5. doi: 10.1006/jsre.2001.6143.

59. Davis EC, Risucci DA, Blair PG, Sachdeva AK. Women in surgery residency programs: evolving trends from a national perspective. J Am Coll Surg. 2011;212(3):320-6. doi: 10.1016/j.jamcollsurg.2010.11.008.

60. Crompton R, Lyonette C. Women's career success and worklife adaptations in the accountancy and medical professions in Britain. Gender Work Org. 2011;18(2):231-54. doi: 10.1111/ j.1468-0432.2009.00511.

61. Weinacker A, Stapleton RD. Still a man's world, but why?. Crit Care. 2013;17(1):113. doi: 10.1186/cc11915 